Revista Iberoamericana, Vol. LXXX, Núm. 246, Enero-Marzo 2014, 241-254

\title{
MITOS Y DELITOS DE CLARIBEL ALEGRÍA: UNA LECTURA CRÍTICO-GENÉTICA DE TRES POEMAS
}

\author{
POR \\ María Auxiliadora Balladares \\ University of Pittsburgh
}

En la prolífica obra de Claribel Alegría (Nicaragua, 1924), podemos observar una constante preocupación por su circunstancia y cómo ésta deviene catalizadora de la poesía. La escritora ha vivido una guerra civil y una revolución en cada uno de sus dos países de origen: El Salvador y Nicaragua. ${ }^{1}$ Ha sido testigo de un siglo sombrío y, en su poesía, ha mostrado siempre su compromiso con una subalternidad tradicionalmente condenada al silencio, la violencia y la explotación. A pesar de que en su obra poética se ha ocupado de esa circunstancia de dolor y muerte, la suya no es una poesía oscura ni densa. Al contrario, es luminosa y siempre libre de pretensiones. Asimismo, la creación poética deAlegría está marcada por un lirismo que recrea con cuidado su universo íntimo, aquel poblado por sus afectos más cercanos, por su familia. La revisión de la génesis de una selección de sus poemas nos permite observar, por un lado, los detalles de un proceso escritural que decanta en un uso cuidadoso y justo de la palabra y, por otro, cómo la escritura deviene constante reescritura (Lois 43), logrando así un refinamiento de las estrategias utilizadas para alcanzar, entre otras cosas, la impresión de oralidad característica de su poesía.

$\mathrm{Al}$ revisar la correspondencia y los cuadernos de trabajo de Alegría en el archivo que reposa en la Biblioteca Firestone de la Universidad de Princeton, nos encontramos en diversas ocasiones con reflexiones suyas en torno a la certeza de que el género en el que se siente más cómoda es la poesía. Alegría, además, ha escrito novela, testimonio, ensayo y también ha sido traductora; sin embargo, es a su obra poética a la que le ha dedicado más años en su trayectoria literaria. Siendo muy niña, José Vasconcelos la incentivó en su amor por los versos y fue este intelectual mexicano quien publicó su primer poemario. Los primeros poemas manuscritos que encontramos en el archivo datan de 1940, es decir, de cuando Alegría contaba con 16 años, y el más reciente poemario

1 El padre de Alegría era nicaragüense y su madre salvadoreña. Aunque ella nació en Estelí, Nicaragua, su familia tuvo que exiliarse en El Salvador por motivos políticos, siendo ella muy pequeña. Allí vivió hasta los 17 años. 
publicado es de 2010. Podríamos decir que un lector de su obra poética puede encontrar en ella lo que la escritora - en uno de sus cuadernos de trabajo, en una entrada fechada el 4 de noviembre de 1998-sostiene son sus tres grandes preocupaciones: Centroamérica, el amor y la muerte. La vida literaria de Claribel Alegría ha sido intensa. Con respecto a su compromiso, podríamos mencionar más específicamente tres aspectos destacados: la Revolución Sandinista, su necesidad de rescatar la memoria histórica de sus países, su vinculación con las luchas de la mujer centroamericana.

Mencionábamos que paralelamente a su vida literaria, su vida personal ha sido igualmente intensa y la relación con su esposo, Darwin J. Flakoll, ha sido determinante. No sólo realizaron en colaboración importantes trabajos de promoción de escritores latinoamericanos y estadounidenses y publicaron libros como Cenizas de Izalco -a propósito del levantamiento indígena de 1932 en El Salvador-, sino que su relación personal devino hito en lo que respecta a la producción poética de Alegría. El amor, para ella, es Flakoll; de aquí que su muerte en 1995 haya significado para la poeta un punto de quiebre. ${ }^{2}$ En 1999, Alegría publica Saudade, que es un poemario melancólico en el que la mayoría de las composiciones evocan el dolor por la muerte del otro y la desesperación por que la propia vida termine, como en "Invocación a la muerte”: "No ya el desasosiego / pero sí el deseo / la esperanza / de encontrarte a la vuelta de la esquina / para cortar de un tajo / el hilo que me clava” (40). Señala Marcia Phillips McGowan a propósito del tono lírico de este poemario y del proceso de su composición:

Initially, after Bud Flakoll’s death, Alegría resolved to write no more poetry. However, she has recently published Saudade (Sorrow), born of her devastation at their parting and her longing to be reunited with "mi otro yo" ("Eres mi otro yo" ["You Are My Other I"] 37). Unlike her earlier volumes of poetry, which so easily meld the political with the personal, Saudade is an almost exclusively individual and intricate exploration of the depths of grief. Herein Alegría invites us to share the pain of lost happiness and her haunting remembrance of things past, as well as to witness the commemoration of a love which transcends time and space. (26)

En 2003 -en versión bilingüe- y 2005 -en versión española-, publica Soltando amarras, poemario en donde, a pesar de que el tono melancólico se atenúa, todavía

\footnotetext{
2 A propósito de la publicación de los poemarios Umbrales (1996) y Saudade (1999), Marcia Phillips McGowan señala: "I would have asserted that despite the turmoil to which she has testified in various forms of discourse, her poetry has left to her readers a testament of hope. However, after reading these last two volumes, I must concede that they convey a sense of diminished hope, not surprising in light of the failure of the 1979 Sandinista Revolution in Nicaragua, the uneasy "military peace" of 1992, the splintering of the Farabundo Marti National Liberation Front (FMLN) and the reported continuance of the death squads in El Salvador, and the illness and ultimately the death of her collaborator, translator, and husband Darwin B. (Bud) Flakoll in spring 1995” (5).
}

Revista Iberoamericana, Vol. LXXX, Núm. 246,
ISSNero-Marzo 2014, $241-254$
ISSN 2154-4794 (Electrónico) 
es posible percibir, en algunas composiciones, la tristeza ante la ausencia inminente, como en "Diste el salto mortal": "Diste el salto mortal / y renaciste / yo sigo en esta orilla / agazapada" (18). Alegría empieza a trabajar en este poemario inmediatamente después de terminar Saudade. El siguiente poemario, Mitos y delitos, que es el que aquí nos convoca, vivió un interesante proceso de conformación. Podríamos referirnos a él como la constatación, para el lector de Alegría, de que el amor -tanto como motivo poético, así como impulso vital- es constante, pero que el sentimiento de nostalgia se ha matizado con los años. Aquí, las certezas de la voz poética, en algunos de los textos, son otras, y aunque siempre remiten a un tú poético cuya cercanía se anhela, ya no se percibe el tono de profunda tristeza de los dos poemarios anteriores y, más bien, la constitución misma del libro apunta hacia un retorno a los grandes temas de su poesía como escritora comprometida.

Aquí revisaremos brevemente el proceso de conformación de Mitos y delitos (2008) y nos concentraremos en una lectura crítico-genética de tres de los poemas que lo conforman. Los textos con los que contamos para esta lectura son básicamente las diferentes versiones publicadas de los poemas a las que hemos podido acceder y versiones dactiloscritas. Estas últimas han sido trabajadas en computadora, herramienta de la que Alegría echa mano desde hace, por lo menos, dos décadas. La escritura de un texto en computadora implica que una parte del proceso genético no va a ser registrada ya que los procesadores de documentos brindan al autor la comodidad de borrar, cortar, copiar, insertar segmentos del poema sin que quede un registro visible sobre la hoja electrónica. Así, se suele guardar solamente una versión "limpia” del texto, que es la que se imprime. Algunos de los documentos impresos con los que hemos trabajado cuentan con tachaduras e inserciones hológrafas sobre las que nos detendremos. En otros documentos, estas tachaduras e inserciones no se dan. En el último caso, hemos procedido a observar las variaciones entre las diferentes versiones.

Mitos y delitos fue publicado por la Colección Visor de Poesía, en España. Consta de 63 composiciones. Al recorrer el índice, se pueden distinguir dos tipos de poemas: unos que evocan algún mito en concreto -ya sea de la Grecia Antigua (15 poemas en total), como "Palas Atenea”, "Fedra”, "Eros"; o de otras tradiciones (8 poemas en total), como "La Malinche”, "La cesta de Moisés”, "Isis"-, y otros (40 poemas en total) -a los que llamaremos "no-mitos" para distinguirlos de los del primer grupo- que evocan ya sea una reflexión lírica ("Nostalgia-cuervo") o en torno a la escritura poética ("Poesía”); o alguna alusión a un género en concreto ("Haiku”). El título del poemario, en primera instancia, podría hacernos pensar que los "mitos" se corresponden con el primer tipo de poemas y los "delitos" con el segundo; sin embargo, cuando nos enfrentamos a su lectura, se percibe que esa deducción no es precisa. La mayoría de los mitos son a su vez delitos: así, la Malinche reclama a su pueblo el haberla entregado a los blancos; Deméter reclama por el secuestro de su hija; Caín admite que mató por envidia a su

\footnotetext{
Revista Iberoamericana, Vol. LXXX, Núm. 246, Enero-Marzo 2014, 241-254 ISSN 0034-9631 (Impreso) ISSN 2154-4794 (Electrónico)
} 
hermano. El segundo grupo de poemas nos remite a otra clase de ejercicio poético. Esto ocurre porque fue compuesto en circunstancias distintas.

En el archivo de Princeton que contiene los documentos de la poeta, en la serie dedicada a escritos y, más concretamente, en la subserie dedicada a poesía, encontramos dos carpetas que fueron armadas, al parecer, con propósitos distintos. En una de ellas, que lleva el título de "Mitos", se encuentran los poemas, en versión dactiloscrita, que a lo largo de las últimas dos décadas, aproximadamente, Alegría compuso en torno a este motivo. Estos poemas habían sido ya publicados en poemarios anteriores; así que se trata de una carpeta en la que la poeta ha recogido textos escritos en el pasado. Consta de 45 poemas (algunos de ellos cuentan con más de una copia) entre los que se incluyen 16 poemas de los que conformarán Mitos y delitos. ${ }^{3}$ En la otra, llamada "Poesía en marcha", sin fecha, encontramos la versión dactiloscrita de una serie de poemas, aparentemente inéditos, y las fotocopias de otros poemas publicados. En esta carpeta se encuentran los poemas que conformarán el segundo grupo (el de no-mitos) del poemario en cuestión. Así, se explica que el libro esté compuesto por dos tipos de poemas distintos. En realidad, Alegría decidió juntar dos proyectos diferentes en un solo libro. Esto último se confirma al revisar la correspondencia de la autora. El día 19 de agosto, 2007, Alegría envía un correo electrónico a su hija Maya Flakoll en el que menciona: "Ya me decidí que los dos libros que tengo en proyecto los reduciré a uno en que se mezclen mitos y otros poemas. Creo que se va a llamar Juego de espejos o Espejismos. Para Navidades veremos todo eso" [CAP B.13, f.2]. De los tres poemas que revisaremos aquí, uno es un mito: "Carta a un desterrado”, y dos son no-mitos: “El colibrî” y "De súbito una brasa".

El poemario completo está dedicado "A Rubén Darío y Robert Graves que me enseñaron a amar los mitos” (7) y a Juan Ramón Jiménez quien fue su maestro en George Washington University y quien corrigió su primer poemario. Además de la nacionalidad, a Darío la vincula el hecho de ser su entusiasta lectora; con respecto a los mitos en particular, vienen a la mente algunos poemas de Prosas profanas, como el “Coloquio de los centauros”. La relación de Alegría con Graves fue muy cercana, entre otros motivos, porque ella y Flakoll tradujeron la poesía de Graves al español y eran vecinos en Deyá, Mallorca. En Mágica tribu, libro que Alegría dedica a los relatos de sus amistades con otros escritores, comenta sobre Graves: "Se mantuvo siempre ajeno a las modas literarias, era un poeta de corte clásico y un gran conocedor de la mitología griega. El latín y el griego los conocía a la perfección. Escribió algunas famosas novelas,

\footnotetext{
3 Estos poemas son: "Carta a un desterrado", "Hécate”, "Ira Demetrae”, "Galatea ante el espejo", "Perséfone”, "Pandora”, “La Malinche”, "Dalila”, “Afrodita”, “Isis”, “Lucifer”, "Palas Atenea”, “Judas Iscariote”, "Faetón (hijo del sol)”, "Prometeo encadenado” y "Clamor de Gaia” (que en otra versión contenida en esta misma carpeta lleva el nombre de "Monólogo de Gaia”).
}

Revista Iberoamericana, Vol. LXXX, Núm. 246,
ISSN 0034-9631 (Impreso) 
como Yo, Claudio, por ejemplo [...] Muchas veces lo acompañé en sus caminatas. Me hablaba de mitología y de las cosas raras que pasaban en Deyá” (81-82). A lo largo de su vida, Graves publicó varios títulos en torno a las mitologías griega y hebrea. Por su lado, el tratamiento que hace Alegría del mito ha implicado una vuelta de tuerca; dialoga con lo que Gwen Kirkpatrick, en "New Creatures from Old Mythologies", ha mencionado es el motivo por el cual es posible encontrar en el corpus de la obra de poetas latinoamericanas constantes y sistemáticas recreaciones de mitos. Señala Kirkpatrick que éstas devienen una estrategia común en el contexto político y social de los años setentas y ochentas.

It may be, as Phillip Slater suggests in The Glory of Hera, that the more a society attempts to restrict women to the domestic sphere, the more awe-inspiring magic and terror become invested in the woman who inhabits this space, thus explaining the presence of powerful female heroines in Classical mythology, in a society known for its low esteem for women. Even in contemporary Spanish American poetry we see the pull of old mythologies, and see women poets appropriating a centuries-old tradition for radically new purposes. ${ }^{4}$

En este sentido, los poemas que Alegría dedica a los mitos son innegablemente contemporáneos. En sus poemas, no hay una voz que relate el mito, sino que, en la mayoría de ellos, el personaje mitológico en cuestión asume la voz poética, dándole al poema el carácter conversacional y el efecto testimonial que, bien han señalado Beverley y Zimmerman, es característico de la poesía de esta escritora. En algunos casos, el interlocutor es otro personaje mitológico, como ocurre en "Galatea ante el espejo": "me forjaste perfecta Pigmalión” (17). En otros, el interlocutor es el mismo lector, como en "Perséfone":

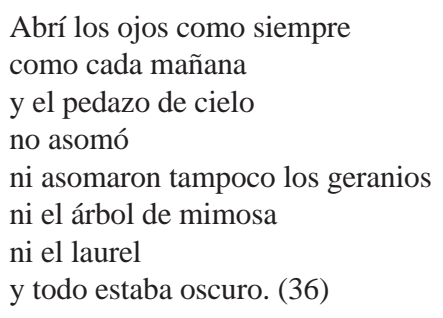

En unos pocos casos, ocurre que hay un yo poético que podría identificarse con la propia autora, como en "Afrodita": "Qué lástima me das / cuando te veo estatua / con los ojos

4 Agradezco a la profesora Kirkpatrick el haberme facilitado la versión inédita de su ensayo.

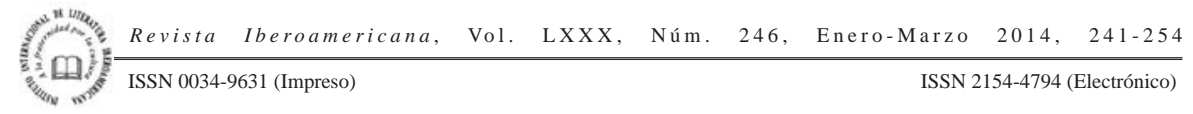


vacíos / sin lujuria en tu piel / sin la alegría loca / de tus cabellos sueltos” (26). En términos generales, se podría decir que los mitos que conforman el poemario nos remiten predominantemente a imágenes de destrucción y de muerte, a la desesperanza generada en el devenir trágico de los personajes. La contemporaneidad de estas imágenes radica en el contexto en el que Alegría las compone: una situación política y social desgastada por la guerra, en donde el estar en el mundo de la mujer se determina por el machismo de la sociedad y por la perpetua violencia. Esa reapropiación del mito es significativa en tanto apuesta a mostrar, por un lado y siguiendo a Kirkpatrick, una sociedad en la que se menosprecia y humilla a la mujer y, por otro, la posibilidad de que el sujeto femenino condenado al silencio tome la palabra, al ser la suya la voz poética en los textos, para poner en entredicho el aparato regulatorio patriarcal y machista. Así, por ejemplo, nos encontramos con una Deméter furibunda que no tiene reparos en acusar a Zeus por haber premiado al secuestrador y violador de Core, al dejar que su hija permanezca una parte del año en el inframundo: "hasta que vuelvas / Core / hasta que Zeus se arrepienta / de su doble moral” (14). En esta línea, sostiene McGowan:

\begin{abstract}
Through re-visioning both Graeco-Roman and Latin American myths, Alegría solidifies her resistance to patriarchal paradigms. Outside the context of war and revolution, another kind of resistance is called for a re-vision of Western myths and archetypes that limit possibilities for women. The retelling of myths from a feminist point of view not only fractures hegemonic discourse, but offers a validation and valorization of many female voices. (17)
\end{abstract}

En el caso concreto del mito de Deméter y Core, la reivindicación en términos hegemónicos se da gracias a la decisión de Deméter de intervenir en el ámbito sobre el que ella ejerce control, el de la tierra y el clima. Mientras su hija permanezca en el inframundo, los campos se volverán infértiles y se enfriará el planeta; dejará la tierra en las manos de los hombres, y ellos arruinarán los paisajes y los sembríos.

En "Carta a un exiliado", la voz poética es la de una mujer, la de Penélope. Ella escribe una carta a Odiseo en la que le cuenta los acontecimientos ocurridos durante su ausencia y le confiesa que está enamorada de un hombre más joven que ha llegado a Itaca. El hombre es el propio Odiseo, a quien, según el mito, en primera instancia, Penélope no logra reconocer cuando éste ha regresado a Itaca y ha dado muerte a sus pretendientes. La identidad de su esposo se revela al lector (no así a Penélope) en los versos: "mi corazón suspira por un joven / tan bello como tú cuando eras mozo / tan hábil con el arco / y con la lanza”. ${ }^{5}$ Ella reconoce la necesidad de que un varón lleve los asuntos de la casa y, al pedirle a su marido que no retorne, que se quede con

5 Antes de dar muerte a los pretendientes de su esposa, Odiseo ha superado la prueba de hacer pasar la flecha por los ojos de 12 hachas seguidas.

Revista Iberoamericana, Vol. LXXX, Núm. 246,
ISSN 0034-9631 (Impreso) 
Calipso o con Circe, se desprende que ella anhela la unión definitiva con el joven, ya que de su amor hacia Odiseo, “no queda ni un rescoldo”. Penélope aconseja a Odiseo no ser soberbio y no invocar a los dioses en tono de venganza. Para esto -y así cierra el poema- le recuerda la obsesión de Menelao con Helena y la "guerra loca” que por su culpa se llevó a cabo, perdiendo en ella la vida los mejores hombre griegos. La carta se cierra con la firma de la autora: “Tu discreta Penélope”.

De este poema, contamos con las siguientes versiones en español: ${ }^{6}$

A: la publicada en la revista Hispamérica, n52, de 1989, pp. 63-65.

B: la publicada en el poemario Fugas de 1993, pp. 52, 54 y 56.

C: la publicada en el poemario Clave de mí de 1996, pp. 183-185.

D: la publicada en el poemario Mitos y delitos de 2008, pp. 59-61; en función de ésta observaremos las variaciones encontradas.

$\mathrm{d}_{1}$ : la dactiloscrita en español sin fecha. [Claribel Alegría Papers [CAP], Princeton University Library, Rare Books and Special Collections, Manuscripts Department [C1363], B. 8, f. 4, 2 pp. s/n].

$\mathrm{d}_{2}$ : la dactiloscrita en español del machote de Clave de mí sin fecha. [CAP, Princeton University Library, Rare Books and Special Collections, Manuscripts Department [C1363], B. 6, f. 5, pp. 171-73]

$\mathrm{d}_{3}$ : la dactiloscrita en español de la carpeta "Mitos” de 2003-2007. [CAP, Princeton University Library, Rare Books and Special Collections, Manuscripts Department [C1363], B. 7, f. 2, 2 pp. s/n]. ${ }^{7}$

En A, la primera versión publicada, encontramos dos versos (los subrayados por mí a continuación) que no vuelven a aparecer en ninguna de las siguientes versiones:

\footnotetext{
6 En el archivo de Alegría, se hallan algunas versiones en inglés de sus poemas. En el caso específico de "Carta a un desterrado", hemos encontrado tres versiones distintas; sin embargo, en este trabajo, nos remitimos exclusivamente a las versiones en español, debido a que referirnos a las traducciones hubiese implicado otro tipo de soporte teórico y otras reflexiones. En el caso de "Ira Demetrae", existen dos versiones completas en inglés y una hoja suelta con el final del poema asimismo en inglés.

7 En los poemas de esta carpeta, hemos encontrado anotaciones hológrafas. Algunas son correcciones o tachaduras sobre los poemas, pero la mayoría son numeraciones que nos remiten, aparentemente, a los diferentes ordenamientos que la autora hizo del índice del poemario. Al parecer, esta numeración se realizó antes de que la autora tomara la decisión de juntar los dos poemarios en uno solo, ya que los poemas que no fueron considerados para Mitos y delitos también fueron numerados. Hacia el final de la carpeta, constan dos versiones diferentes de índices que no coinciden con la ordenación de los poemas en la propia carpeta, ni con la ordenación del poemario publicado, ni con las numeraciones hológrafas a las que nos hemos referido. Sin embargo, si los cotejamos con el índice de Mitos y delitos, podemos observar un par de coincidencias: que, en todos los casos, los poemas "Galatea ante el espejo" e "Ira Demetrae" fueron ubicados al inicio del poemario y los poemas "Dalila", "Lucifer”, "Judas, "Judit” y "Clamor de Gaia" fueron ubicados hacia el final, en la última cuarta parte. Esto indica que si bien posteriormente se juntaron los dos poemarios, la autora preservó, en parte, la lógica de la ordenación original. Aquí hemos decidido trabajar con las variaciones de los poemas y por lo mismo no nos referimos a las numeraciones o a los índices, que podrían ser materia para otro ensayo.
}

Revista Iberoamericana, Vol. LXXX, Núm. 246, Enero-Marzo 2014, $241-254$
ISSN 0034-9631 (Impreso) 
"preferible, Odiseo / que no vuelvas / los hombres son más débiles / no soportan la afrenta. / De mi amor hacia ti / no queda ni un rescoldo" (64). El hecho de que estos dos versos hayan sido eliminados de las versiones posteriores, nos permite hacer al menos dos reflexiones. La primera: parecería que las versiones $\mathrm{d}_{1}$ y d $\mathrm{d}_{2}$ son posteriores a 1989, ya que en ellas tampoco encontramos estos versos. La segunda: el tono del poema, en términos amplios, no es aleccionador; Penélope, el yo poético, se limita a referir los acontecimientos con bastante objetividad. Los dos versos en cuestión, a diferencia del resto, son contundentes en el juicio que emiten. Al eliminarlos, creemos que logra brindarle al poema cierta homogeneidad; ciertamente se trata de dos versos poderosos, pero que desentonan con la discreción característica del discurso de la Penélope de "Carta a un desterrado". Esa discreción es una suerte de "treta del débil", siguiendo el concepto que trabaja Ludmer en su ensayo sobre Sor Juana: ser discreta, en este caso, no implica callar aquello que se desea -ella le pide a Odiseo que no vuelva porque está enamorada de otro hombre-, sino decir lo justo para que el pedido concreto no se desdibuje con la ira de su esposo. Su discreción no se corresponde con la fidelidad que es la característica que tradicionalmente se le ha adjudicado a Penélope. ${ }^{8} \mathrm{Al}$ ser ella discreta, al no decir que él, por ser hombre, es más débil que ella, está exigiendo de su interlocutor la misma actitud cuidadosa. La Penélope de la versión A se permite un exabrupto en el que la Penélope de las versiones posteriores no cae.

En D, cuando Penélope le recuerda a Odiseo que él también la ha traicionado con Calipso y Circe, menciona: "si es Circe la elegida / serás entre sus cerdos / el supremo”. En A, encontramos la siguiente variación: "si es Circe la elegida / serás entre sus chanchos / el supremo". En la palabra “chanchos”, la aliteración de la "ch” le otorga dureza al verso; por el contrario, los fonemas en la palabra "cerdos” son más suaves. La palabra "chancho", según el DRAE, deriva de la palabra "sancho" y se utiliza en América; la palabra "cerdo" es de uso extendido en los países de habla hispana. Así, la variación podría explicarse por el hecho de que, en términos fonéticos, “cerdos” resulta menos duro que "chancho" y porque la primera palabra se utiliza más ampliamente que la segunda. La elección final de los fonemas, aquí, también podría leerse como una treta del débil: suavizar el discurso fonéticamente, a pesar de que semánticamente el contenido no se altera.

Las demás variaciones, en general, nos remiten a cierta indecisión con respecto a la puntuación. Por ejemplo, en A, B, D, $\mathrm{d}_{1} \mathrm{y} \mathrm{d}_{3}$ el poema cierra sin punto final: "Tu discreta Penélope”; pero en $\mathrm{C} \mathrm{y} \mathrm{d}_{2}$, cierra con punto: “Tu discreta Penélope.”. Con respecto a la conformación de los versos, se encuentran apenas tres variaciones: la

8 Nos hemos referido a la confusión de Penélope. Ella no reconoce en el hombre que ha llegado a Itaca a su esposo. El hecho de que se trate de la misma persona se corresponde con la fidelidad, cualidad que este personaje encarna en el mito.

$\begin{array}{lllll}\text { ISSN 2154-4794 (Electrónico) } & \text { Revista Iberoamericana, Vol. LXXX, Núm. 246, }\end{array}$ 
primera, en A, B, C, $\mathrm{d}_{1}, \mathrm{~d}_{2} \mathrm{y} \mathrm{d}_{3}$ : “a tu hijo / y a mí’, mientras que en D (línea 10) : “a tu hijo y a mí”; la segunda, en A, B, D (líneas 23-24), d y d : "tendría yo sin mora / que elegir un esposo", mientras que en $\mathrm{C}$ y $\mathrm{d}_{2}$ : "tendría yo sin mora que elegir un esposo"; la tercera, en $\mathrm{d}_{1} \mathrm{y} \mathrm{d}_{3}$ : “y de / Circe”, mientras que en A, B, C, D (línea 50) y d $\mathrm{d}_{2}$ : "y de Circe”. Asimismo, encontramos una variación en la puntuación de la palabra "Itaca”: en $A, C, d_{1}, d_{2}$ y d $d_{3}$, no lleva acento. En B, se omiten los versos “Telémaco es un niño todavía / y tu padre un anciano.”; en este caso, la omisión resulta sugestiva porque el yo poético no deposita en la situación de otros -la falta de experiencia del hijo y la vejez del suegro- la necesidad de encontrar otro hombre para que rija la casa; aquí, de manera más frontal le hace el pedido a Odiseo de que no vuelva. En $\mathrm{d}_{1}$, se omite "Preferible, Odiseo, / que no vuelvas”; esta omisión se contrapone de forma radical a la que ocurre en $\mathrm{B}$, ya que desaparece el pedido frontal de que no vuelva. Estas dos variaciones nos remiten al hecho de que el poema es un texto epistolar. El gesto de escribir y reescribir una carta hasta encontrar el tono preciso, las palabras adecuadas, es muy similar al de la escritura de las diferentes variaciones de un poema. La conciencia de que el yo se está refiriendo a un tú concreto, hace que, en diferentes momentos del proceso creativo (momentos separados por años en este caso), las certezas sobre lo que ese yo debe decir se alteren. El yo poético se debate, aquí, entre la palabra frontal y la reticencia.

Una última variación importante en este poema se da en el verso: “con Helena”. Tanto en C como en $\mathrm{d}_{2}$, se lee: “con su Helena”. El adjetivo posesivo aparece solamente en Clave de mí y en el machote del mismo libro. Esto quiere decir que, antes y después de este poemario, la poeta no contó con él. Es determinante, en la postura que asume Penélope como mujer, el hecho de desprenderse de cierto uso del lenguaje que podría pasar por amoroso, pero que, en realidad, y en el caso del matrimonio entre Menelao y Helena con más vehemencia, es reflejo de la práctica machista según la cual la mujer es posesión del hombre. ${ }^{9}$ En el proceso en el que se van dando las diferentes variaciones del texto, Alegría va tomando decisiones que nos parece que son importantes y trascendentes debido a las que han sido sus preocupaciones constantes a lo largo de su carrera literaria.

Pasando al segundo grupo de poemas, aquellos que hemos llamado los no-mitos, nos referiremos al poema “El colibrí”. La versión dactiloscrita, $\mathrm{d}_{1}$ [CAP, Princeton University Library, Rare Books and Special Collections, Manuscripts Department [C1363], B. 7, f. 4] reposa en la carpeta "Poesía en marcha”. A continuación reproducimos las dos versiones: ${ }^{10}$

9 Teóricas feministas como Luce Irigaray han hecho énfasis en esta imagen en la que la figura de mujer termina siendo siempre denigrada. En Este sexo que no es uno, Irigaray se refiere al hecho de que tradicionalmente se ha pensado al sexo femenino como un mero receptáculo del miembro masculino y al placer erótico como un placer masculino.

${ }^{10}$ Hemos acogido casi íntegramente la nomenclatura propuesta por Pierre-Marc de Biasi en "Toward a Science of Literature: Manuscript Analysis and the Genesis of the Work”, en el levantamiento de las

Revista Iberoamericana, Vol. LXXX, Núm. 246, Enero-Marzo 2014, 241-254 ISSN 0034-9631 (Impreso) 


\begin{tabular}{|c|c|}
\hline Versión publicada & $\mathrm{d}_{1}$ \\
\hline $\begin{array}{l}\text { EL COLIBRÍ } \\
\text { Mientras liba su flor } \\
\text { vibra en el aire } \\
\text { el colibrí. }\end{array}$ & 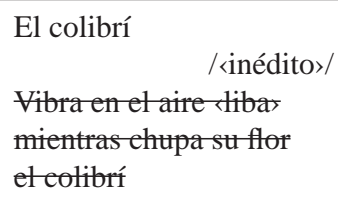 \\
\hline & $\begin{array}{l}\quad \text { Vibra en elaire } \\
\text { «El colibrí } \\
\text { Mientras liba su flor } \\
\text { vibra en el aire } \\
\text { el colibrí〉 }\end{array}$ \\
\hline
\end{tabular}

Jean Franco, en "La gana del alma que es el cuerpo", un ensayo a propósito de las imágenes del bestiario en la poesía de Blanca Varela, dice que lo animal es donde se encuentra la otredad más radical y que enfrentarse a esta otredad implica enfrentarse a sí misma. Podríamos extrapolar esta afirmación de Franco a nuestra lectura de este poema de Alegría. Aquí, la poeta recrea una imagen concreta, que es estática y está en movimiento a la vez. Cuando un colibrí está absorbiendo el néctar de una flor, lo hace manteniendo su cabeza y tronco en una sola posición, pero agitando sus alas al mismo tiempo. El poema inicia con un complemento circunstancial de tiempo: "Mientras liba su flor" y sigue con una afirmación: "vibra en el aire / el colibrí". El acto de vibrar evoca el efecto que ocasiona el movimiento de las alas, pero puede leerse también en términos de la emoción producida en la libación. En un primer nivel de significación, es decir aquel que nos remite a la imagen del animal y la flor, posee una fuerza estética que se corresponde con la belleza del ave, con la brevedad de la escena en conjunción con el laconismo del lenguaje. Volviendo a Franco, ¿qué instancia del ser humano puede reflejarse en la otredad animal del colibrí? El uso del posesivo "su", sobre cuyo uso nunca hay duda porque aparece en las tres versiones del poema que hemos transcrito, nos brinda una primera pista. La poeta está adjudicándole al colibrí la posesión de la flor; hay una vinculación, sin duda, entre el ave y la flor, pero es humano, en realidad, hacer pasar por el lenguaje -escrito en este caso- y por la idea de posesión la relación entre ambos. Es, sin embargo, la dualidad de la imagen (estática y en movimiento a la vez) la más sugerente con respecto a lo que podría ser la esencia del yo poético. Esa

versiones dactiloscritas de este poema y el siguiente:

(> Añadido hológrafo entre líneas

sss Tachadura

〈sss〉 Añadido hológrafo entre líneas tachado

// Añadido marginal.

20vista Iberoamericana, Vol. LXXX, Núm. 246, Enero-Marzo 2014, 241-254 ISSN 0034-9631 (Impreso) ISSN 2154-4794 (Electrónico) 
dualidad se corresponde con lo paradójico del ser humano, con la capacidad de que los opuestos se encuentren en uno; con la fuerza del deseo que se contrapone a la realidad.

En $\mathrm{d}_{1}$, encontramos dos versiones de este poema breve (que debido a sus tres versos evoca a un haiku). La segunda versión es idéntica a la versión publicada. En la primera, encontramos algunas variaciones; por ejemplo, el ordenamiento de los versos se altera. Si en la versión publicada el orden es 1/2/3, en la primera versión de $d_{1}$ es $2 / 1 / 3$. El ordenamiento final hace que el texto fluya más, porque el complemento circunstancial de tiempo ya no funciona como inciso, sino que abre el poema. Es significativo que en la primera versión el colibrí chupa la flor. Toda esa primera versión está tachada, pero igual se nota que se ha hecho una sustitución en letra de la autora y se ha escrito "liba" que es el verbo que se preserva en la versión publicada. La palabra chupar es de tono coloquial, mientras que "libar" o "libación" es una expresión formal, que se encuentra en las traducciones al castellano de textos antiguos para referirse al vino y la leche derramados para honrar a alguien; también aparece en cuerpos de leyes como sinónimo de "beber". Así, la elección final le ha otorgado al lenguaje del poema un tono menos coloquial.

En el mismo grupo de no-mitos, encontramos “De súbito una brasa”. La única variante con la que contamos es una versión dactiloscrita, $\mathrm{d}_{1}$ [CAP, Princeton University Library, Rare Books and Special Collections, Manuscripts Department [C1363], B. 7, f. 4] que se encuentra en la misma carpeta "Poesía en marcha”. A continuación la versión publicada y su variante:

\begin{tabular}{|c|c|}
\hline Versión publicada & Variante \\
\hline $\begin{array}{l}\text { DE SÚBITO UNA BRASA } \\
\text { Mientras aspiraba la blancura } \\
\text { del jazmín } \\
\text { empecé a divagar } \\
\text { empecé a remover } \\
\text { las cenizas del recuerdo. } \\
\text { De súbito una brasa } \\
\text { parpadeó } \\
\text { y alzándose en llama } \\
\text { me susurró al oído: } \\
\text { es un destino sin futuro } \\
\text { el tuyo } \\
\text { y tú tan solo aquello } \\
\text { que ya he dejado atrás. }\end{array}$ & 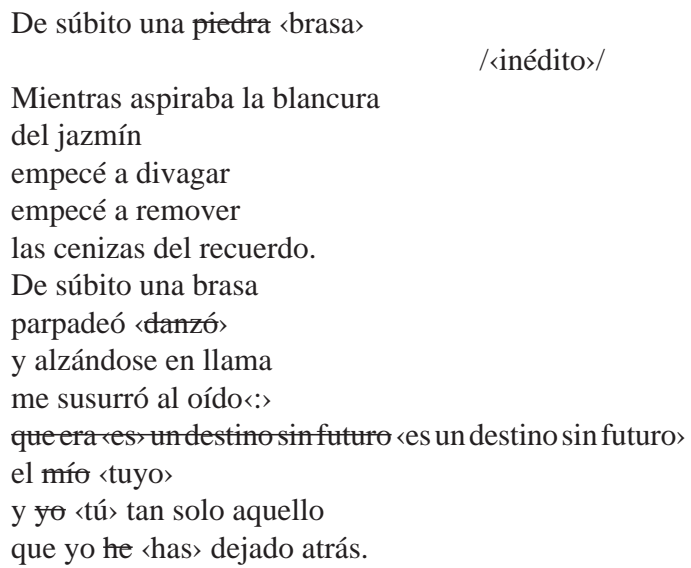 \\
\hline
\end{tabular}

\footnotetext{
Revista Iberoamericana, Vol. LXXX, Núm. 246, Enero-Marzo 2014, 241-254 ISSN 0034-9631 (Impreso) 
La imagen de la brasa es central en el poema. Una llama que se alza desde ella se dirige al yo poético y le dice que la ha dejado atrás. Ese fuego que abrasa objetos no se va a encarnar más en el yo lírico. Ese yo que evoca una memoria del pasado, asume que el suyo es un “destino sin futuro” tal como lo pronostica la llama. El filósofo francés Gastón Bachelard menciona en Fragments d'une poétique du feu: "Les 'temps' alors foisonnent en nous sans trouver la cadence qui réglerait notre durée. Où est le temps qui marquerait d'un trait fort la dynamique de notre être, les dynamismes multiples de notre être. Il suffit de changer d'images pour changer de temps. Dans le règne du feu, nous sommes un brasier d'êtres” (48). El fuego que nos habita sería la posibilidad latente de ser cada uno de esos seres. Bachelard menciona que lo vivido está condenado a ser efímero si es que no puede ser revivido. El yo poético que escarba entre las cenizas de sus recuerdos asume su circunstancia, la imposibilidad de volver a vivir lo vivido, de ser lo que fue en el pasado, de que "los múltiples dinamismos del ser" sean posibilidad latente en ella misma. El poema es bello porque su tono es el de una aceptación tranquila. Sólo ante la certeza de que se ha vivido sin postergaciones e intensamente se puede aceptar un designio de ese calibre, se puede tolerar la "belleza agresiva" -que diría Bachelard- de la verdad que emana del fuego.

El título original del poema, tal como consta en $\mathrm{d}_{1}$, es "De súbito una piedra". Observamos que en la misma versión dactiloscrita se cambia "piedra" por "brasa". La piedra funciona como sinécdoque del tropiezo; sin embargo, el poema, más que evocar un tropiezo, evoca un momento natural en el ciclo vital del ser humano. En $\mathrm{d}_{1}$, asimismo, la poeta duda entre "parpadeó" y "danzó". Tacha el añadido hológrafo “danzó” y se decide finalmente por su primera opción. El verbo danzar denota actividad, movimiento, fuerza; la llama de la brasa de este texto es una llama breve, que apenas susurra; de aquí, quizás, que la autora se haya decidido por "parpadeó”. En d, se utiliza, originalmente el discurso indirecto cuando se le cede la palabra al fuego. Sin embargo, la poeta tacha esos tres versos y los transforma al discurso directo. Las tachaduras en estos poemas son las de sustitución, tal como las llama Biasi (La génétique 54). Sustituir el discurso indirecto por el directo pone al alcance del lector la experiencia vivida por el yo poético. Hay una fuerza externa a ella, al deseo de ese yo, que impone inclusive su voz. La tranquilidad con la que acepta su devenir es índice de aquella aceptación de la muerte del amado a la que nos referíamos al inicio de este trabajo, cuando cotejábamos el tono de Mitos y delitos con los de Saudade y Soltando amarras. Este breve poema, que invita a mirar hacia atrás, que de cierto modo melancoliza en torno al pasado, parece que sugiriera la apertura o el retorno de la práctica escrituraria de Alegría hacia otros ámbitos -más allá del lírico.

En el poema "Ausencia", ese tono de aceptación por la muerte alcanza un punto elevado: "Empieza ya tu ausencia / a serme grata" (18). La decisión de hacer de los dos proyectos un solo libro responde al hecho de que hay una intención de dar a conocer

\footnotetext{
Revista Iberoamericana, Vol. LXXX, Núm. 246, Enero-Marzo 2014, 241-254 ISSN 0034-9631 (Impreso) ISSN 2154-4794 (Electrónico)
} 
algunos de los mitos de Alegría al público español, ${ }^{11}$ pero el hecho de que los mitos se mezclen en un solo poemario con poemas más bien líricos revelaría, asimismo, que ya no hay una necesidad imperiosa por dar cuenta del dolor por la pérdida; ahora es posible abrir la poesía hacia otros horizontes, aunque se trate de horizontes conocidos, los del pasado, los de sus mitos, los de una Alegría comprometida con su espacio y tiempo. La correspondencia de Alegría y sobre todo el cuaderno de trabajo de Soltando amarras, que es, a la vez, una suerte de diario íntimo, revelan el amor profundo de Alegría hacia Flakoll y también muestran el proceso vivido desde finales de la década de 1990 e inicios de la de 2000, que no decanta en el desprendimiento del sentimiento amoroso, sino en una nueva forma de amor, desde el ejercicio constante de la memoria, desde la soledad.

Dado que, según lo habíamos mencionado, los pre-textos con los que contamos para esta investigación son todos versiones dactiloscritas, trabajadas en computadora, hay una parte del proceso creativo de la que no podemos dar cuenta porque se trata de versiones perdidas e irrecuperables de los poemas. Partiendo de esta certeza, se comprende que las variantes a las que nos hemos referido aquí no contengan demasiados cambios con respecto a las versiones publicadas. Asimismo, esto nos impide llegar a la conclusión de que Alegría sea una poeta que casi no inserta cambios en las versiones posteriores a la primera, conclusión que se desprendería de los documentos con los que contamos para este trabajo. Esta suposición termina de descartarse debido al hecho de que en el archivo accedimos a cuadernos de trabajo escritos en letra de la autora que contienen las primeras versiones de textos de otros libros y ahí encontramos que Alegría reescribe sus poemas una y otra vez, alterándolos, a veces de forma radical, otras veces, menos.

Emitir una conclusión definitiva sobre el proceso escritural de Claribel Alegría en función del análisis de los poemas de un solo libro sería poco acertado. Lo que sí podemos señalar, en términos amplios, es que las variaciones que hemos observado en los tres poemas trabajados son mayormente relativas a la puntuación y a las dudas con respecto a preservar o sustituir ciertos términos, así como a la sustitución o supresión de versos enteros. Es claro que hay una tendencia a trabajar las diversas versiones en función de un primer cuerpo textual que aunque no se altera significativamente, ha sido releído con atención y reescrito cuidadosamente por la poeta. Mitos y delitos nos brinda la constancia de que en Alegría la conciencia sobre su tiempo y sociedad va siempre de la mano de su circunstancia personal. Los mitos recreados rezuman actualidad y evocan la mirada atenta de la poeta sobre las relaciones humanas, en general, y la situación de la mujer, en particular. La Core ultrajada de "Ira Demetrae", verbigracia, es una imagen que, amargamente, no deja de reproducirse en nuestros días. Los poemas

11 En un intercambio de correspondencia que mantuve con Alegría en abril de 2011 (“Re: Preguntas”), me comentó que junto con su editor se tomó la decisión de publicar en Mitos y delitos los mitos que hasta ese momento había escrito, para darlos a conocer en España.

\footnotetext{
Revista Iberoamericana, Vol. LXXX, Núm. 246, Enero-Marzo 2014, 241-254 ISSN 0034-9631 (Impreso) ISSN 2154-4794 (Electrónico)
} 
líricos del poemario, por su lado, son breves e intensos en su sencillez; preservan la sutileza de la palabra justa y evocan sentimientos profundos, tensiones, retornos, dudas y certezas. Para Alegría, la poesía es su elemento: "Gracias a ti / Poesía / puedo vivir / mi desamparo" (Mitos 9).

\section{BiBLIOGRAFÍA}

Alegría, Claribel. “Carta a un desterrado”. Hispamérica.18.52 (1989): 63-65.

Claribel Alegría Papers [CAP]. Princeton University Library. «Rare Books and Special Collections [RBSC]», Manuscripts Department [C1363]. Clave de mí. San José: C.R. EDUCA, 1996.

Fugues. (traducido por D. J. Flakoll). Willimantic: Curbstone Press, 1993.

Mágica tribu. Córdoba: Berenice, [2007].

Mitos y delitos. Madrid: Visor Libros, 2008.

"Re: Preguntas sobre Mitos y delitos". Mensaje a María Auxiliadora Balladares.

19 de abril, 2011.

Saudade. Madrid: Visor Libros, 1999.

Soltando amarras. Madrid: Visor Libros, 2005.

Bachelard, Gaston. Fragments d'une poétique du feu. París: Presses Universitaires de France, 1988.

Beverley, John y Marc Zimmerman. Literature and Politics in Central American Revolutions. Austin: U of Texas P, 1990.

Biasi, Pierre-Marc de. La Génétique des textes. París: Nathan-HER, 2000.

"Toward a Science of Literature: Manuscript Analysis and the Genesis of the Work”. Genetic Criticism. Texts and Avant-textes. Jed Deppman, Daniel Ferrer y Michael Groden, eds. Filadelfia: U of Pennsylvania P, 2004. 36-68.

Franco, Jean. "La gana del alma que es el cuerpo". Nadie sabe mis cosas. Mariela Dreyfus y Rocío Silva Santisteban (selección, prólogo y notas). Lima: Fondo de Editorial del Congreso del Perú, 2007. 231-41.

Irigaray, Luce. Este sexo que no es uno. Raúl Sánchez Cedillo, trad. Madrid: Akal, 2009.

Kirkpatrick, Gwen. "New Creatures from Old Mythologies” (versión inédita).

Lois, Élida. Génesis de escritura y estudios culturales. Introducción a la crítica genética. Buenos Aires: Edicial, 2001.

Ludmer, Josefina. “Tretas del débil”. La sartén por el mango. Encuentro de escritoras latinoamericanas. Patricia Elena González y Elida Ortega, eds. Río Piedras: Huracán, 1984. 47-54.

McGowan, Marcia Phillips. "The Poetry of Claribel Alegría: A Testament of Hope”. Latin American Literary Review 32.64 (2004): 5-28.

\footnotetext{
Revista Iberoamericana, Vol. LXXX, Núm. 246, Enero-Marzo 2014, 241-254 ISSN 0034-9631 (Impreso) ISSN 2154-4794 (Electrónico)
} 